\title{
Da semântica estrutural à semiótica das culturas
}

\author{
François Rastier' \\ https://orcid.org/0000-0002-3397-2274 \\ I - Centre National de la Recherche Scientifique \\ Paris, França
}

Resumo: A linguística saussurriana e greimasiana abriu uma tradição de estudos semânticos caracterizada por uma descrição sistemática dos contextos e dos textos. A semântica interpretativa propõe uma teoria unificada, da palavra ao texto e ao corpus. Uma vez que o global determina o local, o corpus de descrição tem uma incidência sobre o sentido do texto, que por seu turno determina o sentido de suas unidades. As aplicações vão da descrição das línguas ameríndias à linguística computacional. Paralelamente à elaboração do conceito de texto, a semântica interpretativa propõe uma nova articulação entre a linguística, a filologia e a hermenêutica. A metodologia adotada é histórica e comparativa. A semântica interpretativa é assim parte integrante de uma semiótica das culturas.

Palavras-chave: interpretação; semântica; corpus; semiótica; linguística.

Abstract: From Structural Semantics to the Semiotics of Cultures - Saussurean and Greimassian linguistics initiated a tradition of semantic study characterized by a systematic description of contexts and texts. Interpretative semantics advances a unified theory that begins with the word and extends to the text and the corpus. Since the global determines the local, the corpus of description has an impact on the meaning of the text, which in turn determines the meaning of its elements. Applications go from the description of Amerindian languages to computational linguistics. Interpretative semantics proposes a new articulation between text linguistics, philology, and hermeneutics. The methodology adopted is historical and comparative. Interpretative semantics thus forms part of a semiotic theory of cultures.

Keywords: interpretation; semantics; corpus; semiotics; linguistics.

O projeto de Greimas, ambicioso, extremamente englobante, apresenta-se de um modo difícil de restituir claramente, pois comporta agendas ocultas que variaram com as épocas. Por exemplo, o percurso gerativo visava combater a gramática gerativa de Chomsky, hoje um pouco esquecida. Além disso, as diferentes fases de sua teoria 
permanecem delicadas de se articular: ao menos, eu não saberia, por exemplo, me pronunciar sobre a maneira de ligar a semântica estrutural à semiótica das paixões.

Tive o privilégio de ler Semântica estrutural em fase de provas; este projeto de semântica textual não perdeu nada de seu mérito. Continuei desenvolvendo o programa da semântica estrutural e alguns disseram, não sem razão, que eu era mais greimasiano que o autor: sempre considerei essa crítica como um elogio.

Enquanto que a semântica estrutural europeia é essencialmente uma semântica lexical, a originalidade de Semântica estrutural reside na sua ligação com uma teoria do texto. Hjelmslev, desde 1943, já havia teorizado a unidade de todos os patamares de complexidade linguística suscetíveis de uma descrição homogênea. O percurso de Greimas vai da palavra (no caso, "cabeça") e de uma lexicologia componencial, à teoria da isotopia, à análise narrativa, e finalmente temática (em Bernanos). Sem dúvida, a ligação permanece problemática - assim como a coerência do todo; contudo, o programa não deixa de ser estimulante.

De minha parte, procurei desenvolvê-lo em três direções complementares.

1. A filosofia da linguagem, quer ela siga a via racionalista da geratividade, quer a via intencionalista da enunciação, conduz a fazer das realidades linguísticas fenômenos de superfície, que não seriam compreensíveis se não a partir de estruturas profundas independentes de toda língua determinada. Uma problemática interpretativa parece então preferível ao modelo gerativo: ela se recomenda da hermenêutica filológica e não da lógica; ela recorre ao reconhecimento de formas semânticas e não ao cálculo. Às profundezas especulativas da enunciação, ela substitui um "modelo plano": dito brevemente, enunciar é passar não de uma obscura estrutura profunda a formas linguísticas, mas de uma palavra a outra: os percursos enunciativos e interpretativos são descritíveis nos mesmos formatos e remetem a uma praxiologia sem aderências ontológicas.

2. Sendo o texto a unidade de base e o objeto empírico da linguística, e considerando que o global determina o local, as unidades de posição inferior, até o sintagma e a palavra (mais precisamente a lexia) devem ser redefinidos e interpretados como passagens de textos - e não como unidades já dadas que seriam posteriormente combinadas.

3. Os textos por sua vez adquirem sentido dentro de "séries": entre língua ("langue") e fala ("parole") se estende o espaço das normas e as principais normas textuais são os gêneros. A linguística de corpus, quando ela persegue o programa da linguística histórica e comparada, permite explorar o domínio das normas textuais e daí descobrir novos dados observáveis. Pode-se ademais distinguir o intertexto das obras, o corpus dos textos, as coleções de documentos (ABLALI; BADIR, DUCART, 2014). 
Para evitar a multiplicação de anedotas a respeito de Greimas, reenvio à tese de Tom Broden (infelizmente inédita) e sobretudo à síntese geral sobre o homem e a obra que ele está finalizando e me permitiu ler alguns extratos.

O percurso dos autores, grandes ou pequenos, é objeto de retrospectivas sempre nostálgicas, frequentemente comoventes, o que desvia a atenção da agenda científica: cinquenta anos após a formação da Associação Internacional de Semiótica, quais são as perspectivas dessa disciplina, suas conquistas, as descobertas que ela pode reivindicar, os novos objetos observáveis? Em quais domínios ela se impôs? Quais são seus programas de pesquisa específicos? Pode ela almejar o estatuto de uma ciência? Desconheço se ela teve essa ambição, dado que os semioticistas permanecem divididos sobre esse ponto, quando, ao menos, consideram que mereça a atenção.

\section{Do quadrado e dos homens}

O quadrado semiótico tornou-se uma pont-aux-ânes da semiótica greimasiana. Estranhamente sou cada vez mais convocado a me explicar a esse respeito, porque ele aparentemente simboliza minha colaboração com Greimas. Na concepção atual que me parece necessária, a evolução aberta após meio século importa mais que minhas lembranças anedóticas. A quais problemas pretendia responder o artigo que, em 1968, apresentava esse ilustre quadrado (GREIMAS, 1970)? Em que permitiu ele sua superação?

O quadrado respondia aos meus olhos à necessidade de sair do binarismo jakobsoniano, integrando outros tipos de oposições e deixando lugar a percursos elementares. Sobre esse ponto, como sobre tantos outros, apreciei muito a liberdade de pensamento de Greimas quando colaborei com ele entre 1966 e 1972. Ele estava em seu melhor período pois é na década 1965-1975 que ele elaborou suas três principais obras (GREIMAS, 1976).

Depois de uma demanda vinda de Seymour Chatman em nome dos Yale French Studies, Greimas, que sabia delegar, pediu-me que escrevesse uma proposição. Discutimos sobretudo pontos de terminologia ao redor de uma garrafa de vodka polonesa.

Quando Greimas retomou este artigo em Du sens, entendi que ele o considerava importante. O "quadrado semiótico", versão enfraquecida do hexágono lógico de Blanché, reelaborado com categorias de Brøndal, era assim promovido ao posto de modelo constitucional da semiótica e colocado à origem absoluta de um modelo gerativo. Foi muito, talvez demasiada honra para uma reflexão sobre a estrutura das classes lexicais elementares desde então incluídas em um "percurso gerativo" que devia explicitamente fazer concorrência ao modelo gerativo de Chomsky, se defrontando, aliás, com os mesmos tipos de objeções. Um modelo potente demais pode satisfazer o desejo irresistível de ver sempre a mesma coisa por todas as partes.

Ainda que o quadrado tenha o mérito de complexificar um pouco o apodítico, seu princípio continua sendo aquele da lógica binária. Ele pode ser útil para apresentações 
didáticas ad usum Delphini. Para os iniciantes, pode ter um papel heurístico permitindo verificar que não se esqueceu de alguma oposição de base. Ele supõe uma lógica elementar de categorias descritivas e convém perfeitamente a um conformismo aristotélico, o que garantiu seu sucesso em ambientes néo-tomistas.

No entanto as relações fundamentais da semiótica saussuriana não são nem oposições nem dicotomias, mas dualidades de pontos de vista, como língua e palavra, diacronia e sincronia, ou ainda significante e significado. E o apodítico é válido somente se se neutraliza a temporalidade e a modalidade introduzidas pelo conceito hermenêutico de ponto de vista.

Ainda que possam utilizar modelizações mais ou menos formais de acordo com as necessidades, as ciências da cultura não podem ser fundadas dedutivamente. Saussure o admitia a respeito de tais célebres dualidades, nas quais cremos ver dicotomias: "Não falamos nem de princípios, nem de axiomas, mas de teses. Essas são simplesmente e no puro sentido etimológico aforismas, delimitações" (SAUSSURE, 2002).

O quadrado, portanto, deve provavelmente sua comodidade ao próprio fato de que ele não permite conceber, nem descrever as dualidades constitutivas do semiótico - em primeiro lugar a semiose que une a expressão e o conteúdo, e que permanece impensável para a lógica binária. Ele não funciona então, paradoxalmente, apenas se não com a condição de não alcançar a meta que lhe é dada, ocultando a complexidade inerente às relações semióticas fundamentais.

Dever-se-ia questionar a epistemologia de uma disciplina que conforma seu objeto a "modelos" intuitivos que servem ao mesmo tempo de metodologia, de heurística e de princípio de exposição, mas que não têm verdadeiramente uma função de objetivação, desde que se considera o objeto como descrito por sua mera aplicação.

A menos de erigir as leis da lógica binária (identidade, não contradição, terceiro excluído) no princípio de todo pensamento: elas estão certamente no fundamento da tradição ontológica ocidental, aquela mesmo que impediu de conceber a autonomia do semiótico e que subordinou a semântica aos problemas metafísicos da referência e da representação. Ao recusá-las com um rigor exemplar, Saussure encontrou soluções (princípio de diferença, negatividade) que rompem com a ontologia. É por isso que ele não foi entendido. E continua-se hoje em fundar a semiótica sobre "il zoccolo duro del Essere" (o núcleo duro do Ser): cito aqui Eco em Kant e o ornitorrinco.

O quadrado perdeu seu caráter fundador com o abandono de fato do modelo gerativo ${ }^{1}$. Ele inclusive se tornou autônomo da teoria semiótica e vive agora sua própria vida. Fui lisonjeiramente convidado a participar em junho de 2012 do terceiro congresso internacional que Ihe foi consagrado.

1 Ele se dividiu em triângulos tensivos que substituíram por curvas as flechas diagonais. Derivado longinquamente do quadrado de Aristóteles, o quadrado semiótico desenvolvia certos pontos da lógica binária enquanto que o modelo tensivo (originado na releitura de Greimas por Zilberberg à luz de G. Guillaume) deriva da tradição augustiniana (Guillaume era presbiteriano). 
Se o formato lógico encontra muito rápido seus limites no domínio semiótico, é porque aí se trata não de cálculo, mas sim de criação e de reconhecimento de formas. Por essa razão, desenvolvi a partir do meio dos anos 1980 uma concepção morfossemiótica do texto, distinguindo, tanto no plano do conteúdo quanto naquele da expressão, fundamentos e formas sobre os quais operam os percursos enunciativos e interpretativos. Seria preciso, ademais, elaborar a noção de horizonte.

Além disso, as unidades não são de modo algum dadas, mas construídas: encontra-se um exemplo simples com o sema aferente; mais geralmente, um sema, como toda grandeza semiótica, é o resultado de um percurso e não seu ponto de partida. Sublinhamos, portanto, a importância da metodologia como constituinte das unidades. Foi um aporte decisivo de Saussure, em especial em De l'essence double du langage (RASTIER, 2015) que clarificou essa questão.

Nossos objetos são complexos e para dar conta deles não podemos partir de uma simplicidade postulada: nenhum elemento nos é dado e, nas ciências da cultura, os dados são aqueles que nos damos. De forma que a composicionalidade permanece ilusória, pois um texto não é uma sequência de frases, uma frase não é uma sequência de palavras, uma palavra não é uma sequência de morfemas, etc.

O simples pode tornar-se o último resultado de uma interpretação. Neste caso, ele é obtido a partir do complexo, do qual ele constitui um "caso-limite": mas é evidentemente necessário detalhar as condições teóricas e metodológicas de sua elaboração.

\section{Semiótica e/ou filosofia da linguagem?}

Por trás da oposição um tanto heráldica entre Saussure (linguista) e Peirce (filósofo e lógico) se coloca uma questão fundamental: a semiótica deriva da filosofia da linguagem ou da ciência das línguas?

Em sua história, a semiótica foi sempre uma parte da filosofia, e mais precisamente da lógica: Locke nomeia a lógica Semiótica, os Senhores de Port-Royal tratam de semiótica em sua Lógica (e não na gramática). Assim, em Semiótica e filosofia da linguagem, Eco retoma sem dificuldade os debates sobre as classificações ontológicas, de Porphyre a Tomás de Aquino e a Kant, utilizando as próprias categorias deles, ora enriquecidas também daquelas de Peirce. Esta tradição milenar continua hoje, embora a linguística histórica e comparada, formada no início do século XIX, tenha abandonado a maior parte de suas principais problemáticas (como a universalidade das categorias mentais, a referência, a classificação ontológica, o dualismo linguagem/pensamento, a categorização).

Um século após a formação da linguística, Saussure testemunhou da complexidade da nova situação suscitada pelo crescimento desta disciplina e formulou o programa de uma "semiologia" elaborada a partir dela. Nesta problemática, os sistemas de signos são evidentemente reconhecidos como formações culturais e não como concretizações de 
categorias universais do espírito humano. A semiótica de inspiração saussuriana é assim uma semiótica das culturas, ao mesmo tempo histórica e comparativa. Em contrapartida, a filosofia da linguagem e a semiótica filosófica permanecem acrônicas (não disse anacrônicas!) e universalizantes.

Como as outras ciências da cultura, a linguística (e em seguida a semiótica, na medida em que ela seja uma disciplina legitimamente instituída e constituída) se caracteriza por sua metodologia histórica e comparativa. Seu objeto pode parecer análogo ou até idêntico àquele da filosofia da linguagem, mas seu objetivo é radicalmente diferente. A filosofia da linguagem, de tradição escolástica² ${ }^{2}$ sempre pesquisou os universais do pensamento, além das diferenças das línguas. A linguística cognitiva deu continuidade a esse programa e, por exemplo, a Lingua Mentalis de Wierzbicka ou o Language of Thought de Fodor retomam a Lingua Mentalis de Occam.

Ao contrário, a linguística - e a semiótica de corrente saussuriana - tomam como objeto a diversidade das línguas e dos outros sistemas de signos; por isso, elas adotam uma perspectiva diferencial, e seu método comparativo pode determinar regularidades gerais - sem, contudo, impor regras universais. A única universalidade permanece então aquela dos universais "de método": foi assim que a linguística nascente definiu, no final do século XVIII, esses seus conceitos, radicalmente novos, de fonema e morfema para poder comparar as línguas, com o sucesso sobre o qual sabemos.

Enquanto a semiótica não tiver esclarecido esse ponto, ela permanecerá como uma filosofia dos signos, certamente estimulante, mas não uma ciência suscetível de produzir novos objetos observáveis e invalidar hipóteses, quão sedutoras elas sejam.

A meu ver, a questão esclarece as dificuldades passadas e também as de hoje: desde a formação da Associação internacional de semiótica, em 1969, duas correntes coabitaram bem ou mal: aquela de inspiração lógica e filosófica (que se refere notadamente a Peirce) e aquela de inspiração linguística (que se apoia em Saussure, mas também em Hjelmslev, e até certo ponto em Benveniste). Não se trata de retraçar a história das guerras picrocholinas que de fato atrasaram o desenvolvimento da disciplina e sua implantação acadêmica, mas devemos interrogar-nos sobre suas razões profundas: nenhuma das duas correntes levou verdadeiramente a sério as ambições científicas de seus iniciadores, seja no domínio das ciências lógico-formais (para Peirce) ou das ciências da cultura (para Saussure). Apesar de iniciativas pessoais meritórias que se mantiveram isoladas, nenhuma dessas duas correntes elaborou um projeto coerente, metodologias e critérios de validação.

Por demais frequentemente, tem-se mantido no estágio do comentário dos autores, quando não do discurso de acompanhamento das mídias e dos produtos diversos das indústrias do entertainment. Não é demasiadamente difícil e responde a uma demanda social, mas não vai além do reconhecimento do que é já conhecido. Deste modo, a semiótica permaneceu na margem, uma margem confortável e um tanto confinada, sem que seus trabalhos pudessem ser retomados ou talvez reelaborados por disciplinas vizinhas.

2 Assim Peirce estende por exemplo Duns Scot; Eco deve muito à Tomás de Aquino, ao qual dedicou sua tese. 
A própria potência das teorias, sua ubiquidade, seu a priori universalista as coloca no domínio da filosofia (quer na filosofia formal de Peirce, quer na filosofia da linguagem de Eco, cujo livro Semiotica e filosofia del linguaggio é perfeitamente claro sobre esse ponto, como ulteriormente Kant e o Ornitorrinco). As teorias científicas, ao contrário, não cessam de relativizar sua potência e de buscar aquilo que poderá as invalidar, de precisar sua metodologia e de descobrir novos objetos observáveis ${ }^{3}$.

Obviamente, a filosofia permanece como uma fonte de inspiração, mas qual? As ciências têm por função depreender a filosofia de seus objetos, de sair do mundo especulativo a caminho do mundo empírico. Como as filosofias da natureza foram depreendidas pela física e pelas demais ciências naturais, a filosofia da linguagem foi recusada pela linguística, da qual ela não partilha nem os objetos nem os objetivos.

A história intelectual da corrente greimasiana marca uma hesitação não resolvida entre linguística e filosofia. O programa científico formulado no artigo "A atualidade do saussurismo", em 1956 (GREIMAS, 1956), parece se formular mais precisamente, em 1966, em Semântica estrutural, mas a relação com a filosofia se mantém implícita: MerleauPonty é evocado, e ao menos uma vez nomeado, mas Husserl não (embora presente).

A partir de meados dos anos 1970, o filão passional prevalece, com aquilo que me parece uma regressão especulativa. Certamente não tenho nada contra a filosofia, contanto que se respeite seus modos próprios de regulação. Desde 1971, busquei legitimar junto a Greimas um diálogo com os filósofos; ele não ocorreu então, e nos anos 1980, as entrevistas com Ricœur não resultaram em uma verdadeira troca. Parecia-me de fato que o sujeito semiótico e o sujeito transcendental formavam um só.

Todavia, a prática descritiva de Greimas, que seja sobre Maupassant ou sobre os contos lituanos, excede consideravelmente suas previsões teóricas. O Maupassant visivelmente queria ir mais longe que o $S / Z$ de Barthes, e conseguiu nisso. Des dieux e des hommes prolonga os melhores momentos de Bédier, Vesselovski, Saussure (sobre as lendas germânicas), Propp.

O atraso da teoria sobre a prática continua sendo, de certo modo, reconfortante, como reconheceram tanto Marx quanto Freud. Resta ainda a reler as leituras de Greimas e delas tirar as lições teóricas mantidas implícitas.

\section{Reconquistar a expressão}

A linguística se constituiu como ciência há um pouco mais de dois séculos, de um lado integrando e superando a gramática e, de outro, rompendo com a filosofia da linguagem, cujas reflexões permaneciam especulativas. Nem a gramática nem a filosofia da linguagem tomavam a diversidade das línguas como objeto, e eis que esse novo objeto científico

3 Por isso, elas acordam-se sobre critérios que não são somente acadêmicos: salvo erro, nenhum congresso da AISS jamais recusou uma comunicação, falta de critérios sem dúvida. 
se vê provido de um método próprio, comparativo e histórico. Ele é compartilhado por todas as ciências da cultura que se formam no mesmo período (antropologia, história das religiões, literatura comparada).

Saussure não pretende nada fundar, mas sim aprofundar uma disciplina que existia já há um século para provê-la de um fundamento metodológico.

(i) Ele o encontra em sua teoria da semiose, que refunda completamente a própria noção de signo, acabando numa noção renovada, da qual o gentil signo isolado do Curso de linguística geral não dá mais que uma imagem ao mesmo tempo falsa e sumária, sem fonte manuscrita.

(ii) Ele a encontra em sua teoria das dualidades exposta de modo decisivo em De l'essence double du langage - uma teoria que ultrapassa o que foi (injustamente) chamado de dicotomias saussurianas.

(iii) Isso se tornou possível somente porque ele rompeu decisivamente com o essencialismo tradicional (que guiava as teorias da referência e da significação), para permitir uma concepção puramente diferencial das "entidades" linguísticas.

O alcance desse dispositivo permite Ihe também conceber uma semiologia geral (não se trata da "vida social" como se pode ler no Cours de linguistique générale, mas "das sociedades" segundo os manuscritos). Por exemplo, a maioria das dualidades são válidas por outras semióticas além das línguas.

Em 1956, no artigo fundador já mencionado, "L'actualité du saussurisme", Greimas sublinha a necessidade de um verdadeiro projeto científico de envergadura para a linguística. De formação histórica e comparatista, ele se situa claramente na corrente saussuriana ilustrada por Hjelmslev, mas também por tantos outros autores essenciais, de Jakobson a Benveniste, Coseriu ou Martinet.

Entretanto, quando no decorrer da década seguinte ele elabora sua própria teoria semiótica e formula seu projeto ambicioso, elevo funda inicialmente sobre uma semântica autônoma em relação à expressão: Semântica estrutural, livro apresentado outrora como fundador da semiótica, não trata desta disciplina. Em seguida, em Do sentido, o projeto de uma semiótica universal e gerativa conduz Greimas a considerar a expressão como uma variável de superfície. Isso garante o caráter transsemiótico de seus modelos, julgados válidos por todos os sistemas de signos: o quadrado semiótico e a estrutura narrativa que dele deriva num nível inferior são dotados assim de ubiquidade. Ora, para Saussure, o conteúdo e a expressão formam uma dualidade e se mantém evidentemente inseparáveis: trata-se de uma única e mesma "entidade", descrita por dois pontos de vista diferentes e complementares. Isso permite entender porque ele, Saussure, não está nada entusiasmado pela semântica de Bréal: ao seu ver, ela negligencia o problema fundamental da semiose. 
Paradoxalmente, ao fundar uma semiótica sobre uma teoria do sentido e não da semiose, Greimas se separa do saussurismo - o que, naturalmente, é o seu direito. Mas sobretudo, ele se priva de poder caracterizar as especificidades de cada sistema semiótico, que dependem precisamente de seus modos de associar expressão e conteúdo, ou para dizer simplesmente, de suas capacidades expressivas.

Com efeito, a perspectiva gerativa, que coloca sempre o sentido in nuce, representada por diversas estruturas profundas, como um termo a quo, conduz inevitavelmente a negligenciar a expressão. A postura gerativa foi uma constante da filosofia da linguagem, das gramáticas gerais da idade clássica, até Chomsky para a filosofia "formal", ou Guillaume e Culioli para a filosofia enunciativa que deve muito à fenomenologia (de Bergson à Husserl). Ela comanda o empírico pelo transcendental.

Nada disso para Saussure, para quem nenhuma profundidade é dada: somente a investigação determina as unidades. Sua concepção hermenêutica da língua e do próprio método científico o conduz a privilegiar os pontos de vista, articulados em dualidades. Os Écrits de linguistique générale permitiram grandes clarificações, notadamente, pode-se apoiar mais firmemente sobre os princípios saussurianos por uma "reconquista" da expressão.

Nada de surpreendente uma vez que a semântica diferencial seja imediatamente uma semiótica (já que a significação se articula sobre a expressão da qual ela é inseparável) - nem que a interpretação permita atualizar, mais precisamente constituir os traços semânticos, que não são preexistentes ao percurso interpretativo do qual eles resultam.

Em suma, o paradoxo da "semiolinguística" é de ter desnudado a semiótica daquilo que ela poderia possuir de linguística e ter considerado a expressão (confundida com o nível linguístico) como uma variável superficial: a potência descritiva da semiótica universal parecia adquirida ao custo de recusar o princípio de base do saussurismo, que consiste na solidariedade do conteúdo e da expressão.

Ela mantém um dualismo tradicional entre inteligível e sensível, profundidade semântica e superfície expressiva (a mesma relação que entre pensamento e linguagem). De onde a tentativa inicial de religar os dois por um percurso gerativo abstrato, e, mais tarde, as evoluções fenomenológicas ou psicanalíticas que procuraram mediações na percepção ou em um Corpo transcendental, como outrora o Espírito absoluto.

Uma semântica que se queira independente ou simplesmente autônoma a respeito da expressão reconduziria ao dualismo matéria / espírito, que sempre atrasou a formação de uma semântica linguística, e justifica ainda hoje o universalismo etnocêntrico da semântica cognitiva.

Paradoxalmente, a semiótica greimasiana vai então ao encontro da semiologia saussuriana assim se fundando como uma semântica universal, transcendente aos diversos sistemas de signos. Contudo, o fundamento da semiótica não se encontra na semântica; como o sentido não pode ser apreendido se não por sua expressão, é a semiose que constitui propriamente o objeto da semiótica. 
Saussure diz que a natureza do signo "é COMPLEXA; se compõe não de A, nem mesmo de a, mas da associação a/b com a eliminação de A, assim como com a impossibilidade de encontrar o signo nem em $b$ nem em a separadamente" ${ }^{\prime 4}$. A oposição matéria / espírito dá lugar à oposição simples / complexo. A complexidade deriva do princípio semiótico ele mesmo: como não há correspondência termo a termo entre conteúdo e expressão, ou seja, como seus dois planos não são "conformes" (a uma expressão compacta pode corresponder um conteúdo difuso, a um conteúdo compacto pode corresponder uma expressão difusa), faz-se necessário problematizar a semiose: todo percurso é complexo, pois ele faz intervir no mínimo dois pólos de uma dualidade.

Mais que saussuriana ou hjelmsleviana, a semiótica greimasiana parece bastante jakobsoniana e praguense (ela aliás não produziu releitura notável de Saussure, e as referências a Hjelmslev no Dicionário de semiótica são evasivas). Ela substitui as dualidades pelo binarismo. A semiótica greimasiana se desenvolveu assim, se distanciando de seu projeto inicial e mais geralmente da linguística, como também de outras disciplinas.

\section{Linguística e semiótica}

O estatuto da linguística parece ter permanecido constituindo o ponto cego da semiótica. Para certos líderes da corrente peirciana, como Sebeok, membro fundador e até há pouco presidente da AISS, os linguistas são dung beetles: qualificando assim seus colegas, entre os quais também me encontro, ele não evocava os hieráticos escaravelhos reais, mas sim suspeitos insetos coprófagos. De sua parte, Greimas, na corrente saussuriana na qual ele se colocava, rompeu de fato com a linguística: não em sua prática, pois continuou uma obra lexicográfica, seja sobre o vocabulário de sua semiótica ou sobre o léxico do francês medieval; mas em sua teoria para a qual a diversidade das línguas é um simples epifenômeno. De fato, a linguística não foi reconhecida como uma semiótica das línguas - enquanto a semiótica tomou por domínio de predileção o visual e, de modo geral, o não linguístico (o design, a media, etc.).

A linguística tem, portanto, todo seu espaço ao lado de outras semióticas regionais, como a semiótica das imagens ou aquela da música. Não vejo nenhuma necessidade de destacar uma semiótica das línguas ou uma semiolinguística que seria outra coisa distinta da linguística, uma semiótica das imagens que não se confunda com a iconologia, uma semiótica da música independente da musicologia: isso seria a fonte de confusões nefastas.

A nós cabe reconciliar, não somente o Greimas tardio com sua juventude, mas a semiótica com a linguística da qual ela é resultante, como com as outras ciências da cultura: uma semiótica da imagem é uma parte da iconologia; a sociossemiótica uma parte da sociologia, etc. Sempre advoguei por uma concepção federativa da semiótica.

As ciências sociais descrevem objetos e performances culturais: as línguas, as instituições, as práticas sociais, as artes, etc. Haviam sido definidas na Alemanha

4 Écrits de linguistique générale, op. cit., p. 131. A seria o conceito, a o significado e $b$ o significante. 
como "ciências do espírito" (Geist), o que me parece sobretudo idealista. Ciências humanas ou ciências sociais? Prefiro falar de Ciências da cultura (o que traduz o termo Kulturwissenchaften). A semiótica não parece uma disciplina entre outras, e talvez foi um erro, em 1969, de a disciplinarizar com a ambição de torná-la um setor acadêmico autônomo. Aliás, essa ambição não foi concretizada. As ciências sociais penam para definir sua especificidade e arriscam fortemente de se ver repartidas entre as "ciências cognitivas" e as "ciências da comunicação", ao custo de uma redução de sua complexidade pelo determinismo genético, ou de sua diluição em meio ao rumor mediático. Os tomadores de decisão raramente apreciam seu ponto de vista crítico, seu interesse pelas descrições qualitativas (e não somente quantitativas), sua reticência, ou até seu ceticismo a respeito do modelo tecno-científico que se desejaria lhes impor.

A semiótica possui vocações aparentemente contraditórias. Uma introdução seria bastante útil no início dos estudos superiores. Mas além disso, uma especialização disciplinar parece necessária (em linguística, sociologia, história, etc.) para evitar criar uma disciplina que se autoriza a falar de tudo. No fim do curso acadêmico, uma opção de semiótica poderia ser aberta após o doutorado, como outrora a hermenêutica era reservada aos doutores, ou, como hoje, a psicanálise (não lacaniana) é uma opção ao fim dos estudos de psiquiatria. Essa questão se mantém, naturalmente, aberta... mas parece necessário que a semiótica se confronte às exigências de outras disciplinas e saia de sua vida interior, aconchegante, mas confinada.

Como partidário de uma semiótica federativa, parece-me que as ciências humanas e sociais de dividam, cada uma a seu nível de análise, a semiótica. Nem puramente interna, nem puramente externa. O semiótico constitui o mundo onde vivemos. Deve-se ainda demonstrar a necessidade de uma ciência particular que seria a semiótica.

\section{A semântica interpretativa}

A linguística saussuriana abriu uma tradição de estudos semânticos caracterizada por uma concepção não referencial e não-composicional da linguagem (Hjelmslev) e uma descrição sistemática de contextos e de textos (Greimas, Coseriu, Pottier). Em seu programa, formulado em meados dos anos 1980, a semântica interpretativa sintetiza essa corrente, reconhecendo as lacunas do paradigma lógico-gramatical para propor uma teoria unificada, da palavra ao texto e ao corpus (reagrupamento estruturado de textos). Uma vez que o global determina o local, o corpus de descrição possui uma incidência sobre o sentido do texto, que por sua vez determina o sentido de suas unidades até o morfema. Como nas gramáticas de construção, o problema da semiose (correspondência dos conteúdos e das expressões) reveste assim um valor criterial.

As aplicações vão da descrição das línguas ameroíndias à linguística computacional. Paralelamente à elaboração do conceito de texto, a semântica interpretativa propõe uma nova articulação entre a linguística dos textos, a filologia dos documentos e a hermenêutica das obras. 
Como o sentido é feito das diferenças, a metodologia adotada é histórica e comparativa, como aquela da antropologia e da maior parte das ciências sociais. Reconhecendo a complexidade das línguas, definidas como formações culturais, a semântica interpretativa é, portanto, parte constitutiva de uma semiótica das culturas. Reconhecendo a complexidade das línguas, definidas como formações culturais, a semântica interpretativa é, portanto, parte de uma semiótica das culturas.

\section{Situação}

Corrente de pesquisa surgida na França em meados dos anos 1980, a semântica interpretativa pertence a corrente saussuriana e se apoia sobre uma síntese da semântica estrutural europeia, desenvolvida notadamente por autores como Louis Hjelsmlev, Eugenio Coseriu, Émile Benveniste, Klaus Heger, Kurt Baldinger, Horst Geckeler, Bernard Pottier e, naturalmente, Greimas (RASTIER, 1987)5.

Nos anos 1970, a perspectiva gerativa dominava na linguística (na corrente chomskiana) e em semiótica (na corrente greimasiana). Ela é herdada das gramáticas filosóficas anteriores à formação da linguística como ciência: trata sempre de explicar os fenômenos linguísticos "de superfície" pelas operações do pensamento sobre estruturas profundas, de tipo lógico, onde se dá uma apresentação axiomática. A problemática interpretativa rompe com esse dualismo tradicional.

Como a expressão e o conteúdo das línguas são inseparáveis, a semântica não pode ser uma disciplina autônoma: ela descreve somente um ponto de vista metodologicamente determinado sobre os signos e deve então ser complementada por um ponto de vista sobre a expressão: a sintaxe (por uma parte), a morfologia, a fonologia e a grafemática descrevem um ponto de vista complementar sobre os mesmos signos. A linguística é então definida como a semiótica das línguas - independentemente da semiótica do positivismo lógico e de sua divisão entre sintaxe/ semântica/ pragmática que não é utilizável pelas línguas.

Relativamente às correntes dominantes que se enfrentam em escala internacional, a semântica cognitiva e a semântica lógica, a semântica interpretativa abre assim uma terceira via. De fato, ela se mantém distinta das duas formas de dualismo, cognitivo e lógico, que se exprimem, uma na separação ontológica entre a ideia e o signo, a outra entre o signo - ou nome - e o referente. Sem hipóteses sobre a teoria do conhecimento ou sobre a ontologia, a semântica interpretativa não trata nem das representações, nem dos objetos do mundo. Ela descreve o sentido das línguas e dos textos orais e escritos sem apelar às realidades conceituais ou mundanas, mas como o produto de diferenças entre signos e outras unidades, tanto em contexto quanto no seio dos textos e dos corpus.

Se o sentido linguístico não consiste em representações, ele exerce restrições sobre a formação das representações; assim, no seio dos textos, as estruturas semânticas favorecem diferentes impressões referenciais.

5 Uma primeira apresentação se encontra na síntese publicada em 1987: François Rastier, Sémantique interprétative. Paris, Presses Universitaires de France, 1987 ( $2^{\mathrm{a}}$ ed. aumentada, $1996 ; 3^{\mathrm{a}}$ ed. 2009). 
Nessa problemática diferencial, o conceito fundamental é aquele de valor. (i) O valor é a verdadeira realidade das unidades linguísticas. (ii) Ele é determinado pela posição das unidades no sistema (portanto pelas diferenças). (iii) Nada preexiste à determinação do valor pelo sistema. Assim, o valor não é um signo, mas uma relação entre signos. Ele exclui uma definição atomista do signo, que lhe atribuiria a priori uma significação pois uma significação é um resultado, não um dado. Ele interdita a definição composicional do sentido, pois enquanto princípio estrutural ele estabelece a determinação do local pelo global. Deve-se então admitir que o conteúdo do signo não é um conceito universal, mas um significado relativo a uma língua, talvez a um texto e a um corpus.

A tradição lógica e ontológica que prevaleceu na gramática e, mais tarde, nas ciências da linguagem isolou a palavra em sua relação com seu referente, a frase em sua relação com um estado de coisas, o texto em sua relação com um mundo, ficcional ou não. A esse paradigma da significação, cujo fundamento é em suma metafísico, nos parece útil de substituir aquele do sentido, outrora de tradição retórica e hermenêutica, para romper a tripla solidão do signo, da frase e do texto: a palavra toma seu sentido no sintagma, o sintagma no período, o período no texto, o texto na prática social onde ele é produto e relativamente a outros textos. Assim, como as línguas não possuem nenhuma "transparência" denotacional ou psicológica, tanto seu conteúdo como sua expressão constituem um domínio de objetivação autônoma.

\section{Princípios gerais}

A. O meio semiótico. - Para evitar isolar os signos e reificar o sentido, parece útil recordar essas teses:

(i) Como a caracterização dos signos depende dos percursos interpretativos, segundo o contexto, o "mesmo" signo poderá funcionar como índice, index, símbolo, etc. O estudo das práticas interpretativas comanda então aquela dos signos.

(ii) O objeto da semiótica não é feito de signos, mas de performances complexas, como a ópera, os rituais, etc. O complexo precede o simples e como os textos orais ou escritos são o objeto empírico da linguística, delimitar os signos exige já operações metodológicas não triviais.

(iii) A caracterização diferencial dos textos e outras performances semióticas supõe a constituição e a análise crítica de corpus.

(iv) Os signos não são por natureza os instrumentos do pensamento nem a expressão das percepções. A semiótica, feita de performances complexas, constitui o meio humano: esse meio não é um instrumento, mas o mundo onde vivemos e ao qual temos de nos adaptar. A problemática interpretativa 
não é mais, portanto, aquela da representação, mas aquela do acoplamento no sentido biológico, entendido como acoplamento cultural com o ambiente semiotizado.

(v) Ainda que a pragmática privilegie o hic et nunc, o ambiente humano compreende uma multidão de objetos ausentes, ou que, ao menos, são desprovidos de substrato perceptivo imediato: eles povoam a zona distal do ambiente semiótico à qual visam aceder tanto as ciências como as religiões ${ }^{6}$. Por que os signos não são referenciais, eles permitem criar mundos.

B. O sentido - Em suma: (i) O sentido é um nível de objetividade que não é redutível nem à referência, nem às representações mentais. Ele é analisável em traços semânticos (ou semas) que são momentos estabilizados nos percursos de interpretação. (ii) A tipologia dos signos depende da tipologia dos percursos dos quais são o objeto. (iii). Feito de diferenças percebidas e qualificadas nas práticas, o sentido é uma propriedade dos textos e não dos signos isolados (que não possuem existência empírica). (iv) O sentido de uma unidade é determinado por seu contexto. Como o contexto é todo o texto, a microsemântica depende da macrosemântica. (v) As unidades textuais elementares não são palavras, mas sim, passagens. Uma passagem tem por expressão um extrato e por conteúdo um fragmento. (vi) No plano semântico, os traços pertinentes são organizados para compor as formas semânticas, como os temas, que se destacam sobre fundos semânticos (as isotopias em especial). As formas semânticas são momentos estabilizados nas séries de transformações tanto ao seio do texto quanto entre textos.

C. Dos signos ao texto. - (i) Se o morfema é a unidade linguística elementar, o texto é a unidade mínima de análise, pois o global determina o local.

(ii) Todo texto procede de um gênero que determina sem os constranger seus modos genéticos, miméticos e hermenêuticos.

(iii) Todo gênero assinala um discurso. Por seu gênero, cada texto se religa a um discurso.[7]

(iv) Todo texto depende de um corpus e deve ser a ele relacionado para ser interpretado.

(v) O corpus preferencial de um texto é composto de textos do mesmo gênero. Os percursos genéticos e interpretativos no seio do texto são inseparáveis dos percursos interpretativos no intertexto estruturado que constitui o corpus.

6 Por oposição com os sistemas de comunicação dos animais, as línguas humanas permitem três tipos de reconhecimento (nos domínios da pessoa, do tempo, do espaço ou do modo notadamente): elas distinguem uma zona de coincidência (zona identitária), uma zona de adjacência (zona proximal) e uma zona distal (a terceira pessoa, o outrora, o lá, o irreal): em suma, elas permitem falar daquilo que não está lá. Os objetos culturais asseguram a mediação entre essas zonas que permitem o acoplamento do indivíduo com seu ambiente semiótico. 
D. As línguas. - Uma língua é feita de um corpus de textos orais ou escritos e de um sistema. O sistema reconstituído pelos linguistas é uma hipótese racional formulada a partir de regularidades observadas no corpus. Entre o corpus e o sistema, as normas garantem um papel de mediação: ancoradas nas práticas sociais, as normas de discurso, de gênero e de estilo testemunham a incidência das práticas sociais sobre os textos que elas abrangem. Para evitar a falsa antinomia entre a língua enquanto sistema de formas e a língua como produto de uma cultura, considera-se que o sistema compreende regras e normas diversamente imperativas; por exemplo, as normas da balada francesa diferem daquelas da balada inglesa.

As regras e normas parecem se distinguir apenas por seu regime de evolução diacrônica. Sabe-se que as palavras (lexias, depois morfemas) são resultado da solidificação e erosão de sintagmas; aquilo que vale por essas unidades linguísticas, vale sem dúvida para as regras que normatizam suas relações e as constituem assim em unidades: as regras são verossimilmente normas discursivas inveteradas.

Em sincronia, toda regra coexiste com normas que acompanham e, possivelmente, condicionam sua aplicação: sem elas, por exemplo, não poder-se-ia deter encadeamentos indefinidamente recursivos, mas gramaticalmente corretos. Pode-se então apenas julgar a gramaticalidade de uma frase se se conhece o discurso, o gênero e o texto ao qual ela pertence - além de, é claro, a datação e o lugar de origem do texto. Ainda que elementar, essa observação permite evitar inúteis discussões sobre a agramaticalidade e assemanticidade que surgem quando se aceita discutir frases descontextualizadas. Assim, diferentemente daquele de uma linguagem formal, o sistema de uma língua é em efeito plural e se declina em regimes estruturais diferentes segundo os níveis de análise. Seus domínios de organização locais ou regionais não são unificados em uma hierarquia atestando a existência de um sistema único e homogêneo, como o testemunha a evolução contínua das línguas que encontram em sua heterogeneidade sistêmica o motor interno de sua mudança perpétua por perturbações e ajustamentos.

De modo que a língua não é jamais o único sistema de normas à obra: um texto (oral ou escrito) é o encontro, na prática, entre uma língua, um discurso, um gênero e um estilo.

\section{Semântica textual - ou macrossemântica}

Formulada em meados dos anos 1960 no quadro da linguística histórica e comparada "continental", o programa de uma semântica dos textos não perdeu nada de sua necessidade e encontra um novo vigor e novos meios com a linguística de corpus. Pode-se atualmente invalidar certas hipóteses e sair enfim do princípio de prazer. Se há originalidade, essa é a de ter seguido uma via independente da filosofia da linguagem 
- sem retomar a absurda tripartição entre sintaxe, semântica e pragmática; e, também, por ter aprofundado um nível de objetividade própria, independente das problemáticas da cognição e da comunicação. Não segui as modas sucessivas e não procurei criá-las. A partir da semântica dos textos, procuro contribuir à evolução da linguística de corpus, ao estudo dos textos literários, científicos e filosóficos. O colóquio que certos semioticistas organizaram em Cerisy permitiu saber mais sobre uma agenda coletiva (ABLALI; BADIR, DUCART, 2014), todo balanço parecendo, entretanto, prematuro.

Um texto é uma sequência linguística empírica atestada, produzida em uma prática social determinada e fixada sobre um suporte qualquer. Pode-se conceber a produção e a interpretação dos textos como uma interação não sequencial de componentes autônomos: temática, dialética, dialógica e tática.

(i) A temática. - A semântica interpretativa descreve o tema como um agrupamento estruturado de semas (molécula sêmica). Não é necessariamente dependente de uma lexicalização particular; nos textos técnicos, os temas têm, no entanto, uma lexicalização privilegiada, talvez até exclusiva.

(ii) A dialética. - Como ela trata dos intervalos de tempo representado e das evoluções que aí se desenrolam, a dialética compreende notadamente as teorias da narrativa. Ela é definida em dois níveis. O primeiro nível, dito acontecimento, aparece em todos os textos estruturados por um componente dialético. Suas unidades de base são os atores, os papéis e as funções - no sentido de tipos de ação representadas. As funções são interações típicas entre atores: essas são classes de processos. Como os atores, elas são definidas por uma molécula sêmica e por semas genéricos: assim, o dom é uma função irênica (de transmissão, à valência ternária), o desafio uma função polêmica (de afrontamento, à valência binária). As funções correspondem às valências actoriais. As funções podem se agrupar em sintagmas funcionais; por exemplo uma mudança se compõe de duas transmissões, um afrontamento de um ataque e de um contra-ataque.

O nível agonístico, hierarquicamente superior ao nível do acontecimento, tem por unidades de base os agonistas e as sequências. Um agonista é um tipo constitutivo de uma classe de atores, uma sequência, uma homologação de sintagmas funcionais. Em geral, a componente dialética dos textos práticos não comporta mais que um nível de acontecimento, enquanto os textos ficcionais ou míticos o redobram por um nível agonístico.

(iii) A dialógica. - A dialógica dá conta da modalização das unidades semânticas em todos os patamares de complexidade do texto. Um universo é o conjunto de unidades textuais associadas a um ator ou a uma fonte enunciativa: toda modalidade é relativa a um local (um universo) e um indicador (ator). 
Por exemplo, quando o narrador de La Couisine Bette fala de uma boa má ação, "boa" remete ao universo de dois personagens, e má a seu próprio universo.

(iv) A tática. - Este último componente dá conta da disposição linear das unidades semânticas em todos os patamares.

Cada unidade semântica, nos distintos patamares de análise, pode assim ser caracterizada em função de quatro componentes. Apenas uma decisão metodológica pode isolar esses quatro componentes em interação simultânea e não hierárquica.

No patamar textual, como nos outros, as unidades resultam de segmentações e categorizações sobre as formas e os fundos semânticos, que se pode designar pelo nome geral de morfologias. Seu estudo se divide em três seções: ligações entre fundos, no caso, por exemplo, dos gêneros que comportam mais isotopias genéricas, como a parábola; ligações entre formas; e, sobretudo, ligações de formas a fundos, essas últimas ligações sendo cruciais para o estudo da percepção semântica (RASTIER, 1991).

De acordo com os componentes, as morfologias semânticas podem fazer o objeto de diversas descrições. Por exemplo, relacionado aos quatro componentes, um agrupamento estável de traços semânticos (ou molécula sêmica) pode ser descrito como tema, como ator, como finalidade ou fonte de um ponto de vista modal, como lugar na linearidade do texto. Ademais, para cada componente correspondem tipos de operações produtivas e interpretativas.

A descrição deve restituir o aspecto dinâmico da produção e da interpretação dos textos. A primeira etapa consiste em descrever as dinâmicas de seus fundos e de suas formas: por exemplo, a construção de moléculas sêmicas, sua evolução e sua dissolução eventual. Essas dinâmicas e suas otimizações são combinadas diferentemente segundo os gêneros e os discursos, pois as formas e os fundos são constituídos e reconhecidos em função de normas diferentes: a percepção dos fundos semânticos parece ligada a ritmos e aquela das formas a contornos, cuja organização prosódica pode apresentar uma imagem.

Assim, o sentido de um texto não se deduz a partir de uma sequência de proposições, mas resulta do percurso de formas macrossemânticas que revestem uma significação própria, por seu desenrolar e mediante as valorizações envolvidas. Reencontram-se assim, na compreensão de textos, problemas análogos àqueles que coloca o reconhecimento de formas incompletas ou perturbadas por ruído.

A concepção morfosemântica do texto pode ser modalizada pela teoria dos sistemas dinâmicos. Os fundos semânticos aparecem, então, como sequências de pontos regulares, enquanto as formas são discretizadas por seus pontos singulares (RASTIER, 1999).

Assim, para além de uma concatenação de símbolos, pode-se conceber o texto como um curso de ação semiótico ${ }^{7}$. O gênero codifica a condução desta ação, mas aquilo que se poderia chamar o ductus particulariza um enunciador e deveria permitir caracterizar o estilo semântico pelos ritmos e traços particulares dos contornos das formas.

7 Um texto, parte semiótica de uma prática social, participa de um conjunto codificado de ações. 
A geração de um texto consiste em uma série de metamorfismos (relações de transformação entre formas) e de transposições (transformações de relações entre formas e fundos) que se pode colocar em evidência no oral pelo estudo das reformulações, e no escrito por aquele dos rascunhos. Sua interpretação consiste em boa parte na identificação e avaliação dos metamorfismos: por exemplo, o sentido de uma narrativa é articulado pelas transformações temáticas e dialéticas.

\section{Semântica de corpus - ou megasemântica}

O texto isolado não possui mais existência do que a palavra ou a frase isoladas: para ser produzido e compreendido, ele deve se relacionar a um gênero e a um discurso, e esses, por sua vez, a um tipo de prática social.

Um corpus é um reagrupamento estruturado de textos integrais, documentados, eventualmente enriquecidos por etiquetagens e reunidos: (i) de maneira teórica reflexiva levando em conta os discursos e os gêneros, e (ii) de maneira prática em vista de uma gama de aplicações.

Algumas precisões se impõem aqui. (i) O arquivo reúne o conjunto de documentos acessíveis para uma tarefa de descrição ou uma aplicação. Ele não é um corpus pois não é constituído por uma pesquisa determinada. (ii) O corpus de referência é constituído pelo conjunto dos textos com os quais o corpus de estudo destacar-se-á por contraste. (iii) O corpus de estudo é delimitado pelas necessidades da aplicação. (iv) Enfim, os sub-corpus de trabalho variam de acordo com as fases de estudo e podem conter apenas passagens pertinentes do texto ou dos textos estudados.

Os corpus não são portanto simples reservatórios ou meros agrupamentos de textos. Conquanto sejam constituídos de maneira crítica, levando em conta os gêneros e os discursos, apoiando-se nas indispensáveis garantias filológicas, eles podem se tornar o lugar de descrição dos três regimes da textualidade: genética, mimética, hermenêutica. Um texto encontra suas fontes em um corpus, ele é produzido a partir desse corpus e deve ser mantido nele ou religado a ele para ser corretamente interpretado: o regime genético e o regime hermenêutico se regulam assim um sobre o outro. Quanto ao regime mimético, que determina a impressão referencial, ele depende também do corpus e, em especial, da doxa que ele testemunha.

A correlação confirmada entre variáveis globais como o discurso, o campo genérico, o gênero e as variáveis locais (tanto morfosintáxicas quanto gráficas ou fonológicas), conduz a colocar o problema da semiose textual (RASTIER, 2011). Define-se ordinariamente a semiose no patamar do signo, como uma relação entre significado e significante. Ora, um gênero define precisamente uma relação normatizada entre significante e significado no patamar textual: por exemplo, no gênero da novela, o primeiro parágrafo é frequentemente uma descrição, não uma introdução como num artigo científico. A semiose local e 
condicional proposta pela língua nos patamares de complexidade inferiores, do morfema à lexia, não se torna efetiva a não ser se ela for compatível com as normas de gênero ou, até mesmo, de estilo que garantem a semiose textual.

\section{Aplicações}

As aplicações interessam os domínios disciplinares relativos aos textos, que se tratem de corpus antigos ou contemporâneos e que eles sejam literários, filosóficos, científicos ou mediáticos.

(i) Linguística descritiva. - A semântica interpretativa foi utilizada em estudos sobre línguas romanas e línguas ameríndias (ver especialmente os trabalhos de Enrique Ballón-Aguirre e seus colaboradores sobre o vocabulário agrário do quéchua e sobre o chipaya) (BALLÓN-AGUIRRE; CERRÓN-PALOMINO, 1992; 2002, 2011).

(ii) Semântica dos textos - A semântica interpretativa sendo primeiro uma semântica dos textos, encontra aplicações em múltiplos domínios, por exemplo os corpus literários antigos e modernos (AMIRI, 2004; BALLÓN-AGUIRRE, 2001; CANONROGER; CHRISTINE CHOLLIER, 2009; CHOLLIER, 2014; YONG HO CHOI, 2006; BOTCHKAREV, 1999; MÉZAILLE, 2003; GÉRARD, 2007) ou ainda os corpus filosóficos (LOISEAU; RASTIER, 2011, pp. 73-93) e científicos (VALETTE, 2003, pp. 55-74) ou sobre os artigos de linguística (POUDAT, 2006). Alguns desenvolvimentos didáticos privilegiam a exploração de corpus numéricos no ensino da gramática e da literatura.

(iii) Tratamentos automáticos e linguística de corpus. - A semântica interpretativa aplicada à linguística dos corpus é chamada a renovar os domínios da pesquisa de informação e da representação dos conhecimentos (PINCEMIN, 1999; TANGUY, 1997; THLIVITIS, 1998; BEUST, 1998; PERLERIN; ROY, 2007). Em particular, ela pode favorecer aplicações que são o objeto de uma demanda social crescente: reconhecer um tipo de texto pelas características lexicais ou morfológicas; detectar um tipo de local; auxiliar a análise temática; definir as proximidades entre textos, etc. A maior parte das aplicações supõem hoje tarefas de caracterização: no seio de um corpus, trata-se de singularizar os elementos pertinentes para a aplicação. Assim, a linguística reencontra, por uma nova via, a problemática da descrição das singularidades, própria às ciências da cultura; a descrição de leis, há muito julgada a condição necessária da cientificidade, se subordina então ao estudo sistemático dos usos efetivos. A linguística de corpus participa desse modo do programa de comparação entre línguas, mas sobretudo ela permite continuar esse programa no seio mesmo de cada língua, comparando entre eles os discursos, os gêneros e os textos (BOURION, 2001; RASTIER, 2011). 
(iv) Semióticas não linguísticas e semiótica das culturas. - Os princípios metodológicos que presidem a constituição crítica de corpus valem por todos os documentos numéricos, por exemplo, pelos corpus de fotos (KANELLOS; THLIVITIS; LÉGER, 2000) ou sobre os sites da web (BEAUVISAGE, 2004). Uma síntese sobre as linguagens de ícones foi publicada faz longo tempo (VAILLANT, 1999). Outros domínios, como as narrativas virtuais interativas, são também explorados (CAVAZZA; PIZZI, 2006).

\section{Dificuldades e perspectivas}

A semiótica, após a fundação da Associação Internacional de Semiótica em 1969, não cessou de escrever e reescrever sua história imediata, cada escola aproveitando-a como um instrumento de promoção. Esta história imediata assume por vez uma forma jornalística que esquece tanto os esforços epistemológicos necessários, quanto a convivência com as obras dos fundadores reconhecidos ou proclamados. A semiótica teve, sem dúvida, um número excessivo de fundadores para poder ser uma disciplina certa de si mesma. Independentemente das questões acadêmicas ou bibliográficas, ela deve ainda tornar mais claros seus princípios teóricos, seus problemas científicos, suas metodologias descritivas, seus testes de validação, seus objetos novos. Falta de clarificações, ela poderia tornar-se um simples discurso de acompanhamento das mídias e da indústria cultural. A televisão fala do cinema, o rádio fala da televisão, os blogs falam de tudo e, sobretudo, deles mesmos: faz-se um semioticista intervir no final da linha, e a gente se mantém na bolha comunicacional da sociedade do espetáculo. A semiótica merece mais do que tornar-se uma "tudo-logia" ${ }^{8}$, tratando De omni re scibili et quibusdam aliis. Admiro os semioticistas que, considerando-se competentes para todos os assuntos, falam um dia sobre as cerâmicas Tang, no dia seguinte de Lyotard, logo após, de Saint Bonaventure ou do Chanin Building. Essa agilidade mediática acompanha a integração progressiva da semiótica às disciplinas da comunicação na qual ela pode assumir o papel auxiliar de uma filosofia pop.

Falta por conseguinte identificar os problemas científicos, as hipóteses, os métodos, os procedimentos de validação; se não, substitui-se a argumentação pela menção ou o name dropping e fica-se no estado das opiniões, o que faria da semiótica uma ideologia comunicacional dentre outras. Pretende a semiótica manter-se ou tornar-se um discurso de acompanhamento da comunicação? Claro, pode-se admirar a indústria cultural e aprovar seu louvor ao mundo mercantil, do qual ela provém; mas a semiótica merece sem dúvida ter outras ambições.

Estamos diante de uma alternativa epistemológica: deve-se criar uma trans-semiótica que vai cobrir a totalidade das ciências humanas ou uma inter-semiótica que as federe? Sou defensor, nesta matéria, de um federalismo que respeite as autonomias. As ciências

$8 \quad$ Plageio aqui a palavra italiana tuttologia. 
humanas estudam todos os objetos semióticos, mas permanecem diferenciadas. Desse ponto de vista, a semiótica deve evitar tornar-se ou continuar sendo um tipo de filosofia da significação, como ela poderia se poupar de tornar-se uma ciência das ciências. Melhor seria considerar cada uma das ciências humanas como uma semiótica particular. Isso me parece necessário para estender a problemática do texto (de tradição retórica e hermenêutica) ao estudo das performances semióticas complexas: cinema, ópera, textos multimídia, rituais, jogos interativos, etc. Além disso, somente os percursos enunciativos e interpretativos permitem superar a heterogeneidade aparente dos diferentes sistemas de signos em interação em uma performance semiótica. Alias, um princípio de base da semântica interpretativa reconhece que o interpretante externo de uma relação sêmica no seio de um texto pode pertencer a um outro texto ou a uma outra manifestação semiótica. Assim, a semântica, concebida como descrição de percursos, pode propor, ao preço de um necessário aprofundamento, o quadro teórico da intersemiótica que faz hoje o objeto de uma grande demanda social.

Ao passo que as teorias semióticas tradicionais são essencialmente teorias da representação e que supõem uma ontologia para garantir a categorização e a discretização dos objetos representados, a semiótica interpretativa é fundada sobre uma teoria de ação, ou praxiologia. Desse modo, ela supõe uma deontologia e se abre em direção das disciplinas da ação, daquelas mais aplicadas, como a ergonomia, às mais reflexivas, como a ética.

A linguística histórica e comparada foi criada no contexto de um projeto antropológico geral, do qual Humboldt foi um iniciador eminente, e que articula o universalismo dos Iluministas com a descrição sistemática das particularidades. Em um sentido amplo, a antropologia semiótica envolve tudo aquilo que não é a antropologia física e a biologia humana. Em um sentido mais preciso e mais técnico, a reflexão sobre as propriedades que caracterizam as línguas (em contraste com os sistemas de comunicação dos animais) permite extrair princípios gerais, tal como a estruturação do universo semiótico humano em zonas antrópicas (identitária, proximal, distal) ${ }^{9}$. A possibilidade de evocar e tratar objetos ausentes permite estabelecer e delimitar a zona distal ${ }^{10}$. Seria preciso detalhar também os problemas da transmissão (que evidentemente ultrapassam a comunicação), da dívida simbólica, da antropologia do dom e da troca aplicada às performances semióticas.

As especificidades das línguas humanas interessam a prosódia, os fundos e as formas semânticas e expressivas, a textualidade e a intertextualidade, a semiose. Em suma, as dualidades saussurianas continuam próprias às línguas e às semióticas humanas ${ }^{11}$. Os objetos culturais podem bem depender de suas condições de elaboração e interpretação, os valores que concretizam podem, todavia, ser objetivados como fatos. Por toda parte,

9 Veja-se mais acima "Princípios gerais" (v) e nota 16.

10 Para se aprofundar o leitor curioso poderá consultar um primeiro programa, publicado em 2001 no Jornal dos Antropólogos.

11 Em certas espécies de macacos, como aquele de Campbell, encontra-se uma morfologia e uma sintaxe rudimentares que combinam os sinais de alerta; mas, como dizia Peter Gärdenfors, esperamos sempre que Kanzi, o chimpanzé vedete, nos conte uma história ao redor de uma fogueira. 
trata-se agora de corpus numéricos, quer se trata de música, imagens fixas ou animadas, danças, quer de performances polissemióticas como o cinema, a ópera, os rituais, etc. A exigência científica de descrever tais corpus encontra aqui a demanda social. Com corpus numéricos, as ciências da cultura encontram assim novas perspectivas epistemológicas e metodológicas, talvez um projeto federativo.

Como reconciliar a linguagem e o pensamento, o conteúdo e a expressão, a universalidade postulada do espírito humano e a diversidade das culturas? Como descrever o ambiente humano, massivamente semiotizado? Deve-se ultrapassar as teorias sobre a origem da linguagem para melhor compreender a emergência da semiótica, apoiando-se notadamente sobre as recentes conquistas da linguística e da antropologia. Como as línguas são obras humanas mais que produtos providenciais da evolução, as oposições sumárias entre inato e adquirido, natureza e cultura devem ser relativizadas. Esta tarefa cabe à semiótica das culturas, para evitar que nossa espécie desapareça antes mesmo de ser descrita.

A história da semiótica no meio século que foi transcorrido permanece a explorar; mas sobretudo, um projeto científico deve ser elaborado para os próximos anos.

Tradução de Ana Claudia de Oliveira.

François Rastier é semioticista, doutor em linguística e diretor de pesquisa junto ao Centre National de la Recherche Scientifique (CNRS, Paris). No seu campo de pesquisa estão a semântica interpretativa, as ciências cognitivas, a semiótica das culturas, a linguística e semântica de corpus, entre outros. Dirige a revista eletrônica Texto! Entre as suas publicações junto a PUF destacam-se: Sémantique interprétative, Sémantique et recherches cognitives e Arts et sciences du texte.

frastier@gmail.com

\section{Referências}

Sites gerais

Signo, site Internet bilingue de théories sémiotiques : www.signosemio.com Texto! Textes et cultures (revue électronique): http://www.revue-texto.net

ABLALI, D.; BADIR, S.; DUCART, D. (Eds.). Documents, textes, œuvres. Rennes: Presses Universitaires de Rennes, 2013.

AMIRI, B. Chaos dans l'imaginaire antique de Varron à l'époque augustinienne. Etude sémantique et herméneutique. Nancy: ADRA, (diffusion de Boccard), 2004.

BALLÓN-AGUIRRE, E. Desconcierto barroco. México: UNAM, 2001. 
De la semántica componencial a la semántica interpretativa (el léxico agrario andino). Perfiles semióticos, 1, 2003.

.Tradición oral peruana. Literaturas ancestrales y populares, 2 vol. Lima: Fondo Editorial de la PUC, 2006.

BALLÓN-AGUIRRE, E. CERRÓN-PALOMINO, R. Vocabulario razonado de la actividad agraria andina - Terminología quechua. Cuzco: Centro de Estudios Regionales Andinos "Bartolomé de las Casas", 1992.

Terminología agraria andina - Nombres quechumaras de la papa. Lima: International Potato Center - Centro de Estudios Regionales Andinos "Bartolomé de las Casas", 2002.

. Chipaya. Léxico y etnotaxonomía. Lima: Radboud Universiteit Nijmegen - Fondo Editorial de la PUC2011.

BEAUVISAGE, T. Sémantique des parcours des utilisateurs sur le Web. Thèse de doctorat: Université Paris X, 2004.

BELGHANEM, A. Sémantique du discours scientifique de Pierre Bourdieu. Construction et classification d'un corpus de travail. Texto!, XVII, 4, 2012. Disponível em: http://www.revue-texto.net/index. php?id=3068

BEUST, P. Contribution à un modèle interactionniste du sens. Amorce d'une compétence interprétative pour les machines. Thèse d'informatique: Université de Caen, 1998.

BEUST, P.; FERRARI, S.; PERLERIN, V. NLP Model and Tools for Detecting and Interpreting Metaphors. In: ARCHER, D. et al (Eds.). Domain-Specific Corpora, Corpus Linguitics, Proceedings of the Corpus Linguistics 2003 conference, University Centre for Computer Corpus Research on Language, vol. 16, 2003.

BOTCHKAREV, A. Le motif végétal dans "A la recherche du temps perdu". Villeneuve d'Ascq: Presses universitaires du Septentrion, 1999.

BOURION, E. L'aide à l'interprétation des textes électroniques. Thèse: Université de Nancy II, 2001. Disponível em: http://www.texto-revue.net

CANON-ROGER, F. Traduction et réélaboration interprétative. Revue Française de Linguistique Appliquée, XIV, 1, 2009.

CANON-ROGER, F.; CHOLLIER, C. Des genres aux textes. Essais de sémantique interprétative en littérature de langue anglaise. Arras: Artois Presses Université, 2008.

A Comparison of Several Interpretations of 'Snow' by Louis MacNeice. Imaginaires: I'interprétation au pluriel: Presses Universitaires de Reims, 2009.

CAVAZZA, M. O.; PIZZI, D. Narratology for interactive storytelling: a critical introduction. In GOBEL, $S$ et al. (Eds.). Technologies for interactive digital storytelling and entertainment (Lecture notes in computer science, 4326). Berlin: Springer, 2006.

CHOI, Y. H. Tekst Umiron Kwangei (Course in Text Semantics). Seoul: Ingan Sarang, 2004.

Discursive space - an introduction to Text Semantics. Semiotic Inquiry, 12, 2002.

. Text Semantics of François Rastier: a critical reading about the short story of Bernard Werber. French Studies, 30, 2004.

. Umi wa Sulwhasung (Meaning and narrativity). Séoul: Ingan Sarang, 2006.

CHOLLIER, C. Essai d'interprétation des rythmes sémantiques dans The Heart Is A Lonely Hunter de Carson McCullers. Imaginaires, 11, 2005, Reims: Presses universitaires de Reims. 
Rôles créateurs des contextes dans les parcours interprétatifs des passages. Texto!, XV, 3, 2010, http://www.revue-texto.net/index.php?id=2662.

Textual Semantics and Literature: corpus, texts, translation. Signata, 4, 2014.

DJAOUD, S. Quelques processus d'élaboration de concepts sur le Maghreb dans les sciences sociales (Jullien, Bourdieu et Tillion). Texto !, XIV, 1, 2009, http://www.revue-texto.net/index.php?id=2165

DUTEIL-MOUGEL, C. et al. Semiotics and semantic: tools for an effective appropriation of information, communication and health technologies. Medetel 2012, The International eHealth, Telemedecine and Health ICT Forum For Education, Networking and Business, Luxembourg, 2012.

GÉRARD, C. Sémantique et linéarité du texte. La place du rythme en sémantique des textes. In: Ballabriga M. (Ed.). Rythme et textualités. Toulouse: Éditions Universitaires du Sud, 2007.

GREIMAS, A. J. Sémantique structurale. Paris: Larousse, 1966 (rééd. PUF, 1986).

. Du sens. Paris: Seuil, 1970.

Maupassant. La sémiotique du texte. Paris: Seuil, 1976.

GREIMAS, A. J.; RASTIER, F. The interaction of semiotic constraints. Yale French Studies, 41, 1968. (Repris in A.J. Greimas, Du sens.)

HÉBERT, L. Introduction à la sémantique des textes. Paris: Honoré Champion, 2001.

KANELLOS, I. Patrimonial Traditions Meet Educational Preoccupations: The Interpretive Shift of the Accessibility Requirement. Innovative Methods for Science Education. History of science. ICT and Inquiry Based Science Teaching. Berlin: Frank \& Timme, 2012.

KANELLOS, I.; THLIVITIS, T.; LÉGER, A. Indexation anthropocentrée d'images au moyen de textes: arguments théoriques et directions applicatives du projet SEMINDEX. Cognito, 17, 2000.

LOISEAU, S. Investigating the interactions between different axes of variation in text typology. In: GRZYBEK, J.; KELIH, E. (Eds.). Text and Language: Structures, Functions, Interrelations. Vienne: Praesens, 2010.

LOISEAU, S.; RASTIER, F. Linguistique de corpus philosophiques: I'exemple de Deleuze. In: MANIGLIER, P. (Ed.). Le moment philosophique des années 1960 en France. Paris: PUF, 2011.

MÉZAILLE, T. Accès sémantique aux banques textuelles. L'exemple de Balzac. Champs du Signe, 10, 2000.

La blondeur, thème proustien. Paris: L'Harmattan, 2003.

MISSIRE, R. Unités linguistiques à signifiant discontinu, du morphème au texte. Une approche néosaussurienne. In: Bronckart, J.-P.; BOTA, C.; BULEA, E. (Eds.). Le projet de Ferdinand de Saussure. Genève: Droz, 2010.

Rythmes sémantiques et temporalité des parcours interprétatifs. In: BALLABRIGA, M.; MPONDO-DICKA, P. (Eds.). Rythme, Sens et textualités. Linguistique, sémiotique du discours, sémantique des textes, rhétorique, stylistique, poétique, Toulouse: Editions Universitaires du Sud, 2007.

. Norme(s) linguistique(s) et afférence sémantique: une lecture de Sémantique interprétativ à partir d'Eugenio Coseriu (sistema, norma y habla). Texto!, IX, 4, 2004.

. Une larme baudelairienne, essai de description morphosémantique de Tristesses de la lune. Champs du signe, 20. Toulouse: Éditions Universitaires du Sud, 2005.

PERLERIN, V. Sémantique légère pour le document. Thèse d'informatique: Université de Caen, 2004.

PINCEMIN, B. Diffusion cible automatique d'informations: conception et mise en œuvre d'une linguistique textuelle pour la caractérisation des destinataires et des documents. Thèse de linguistique: Université Paris IV, 1999. 
Sémantique interprétative et textométrie. Corpus, 10, 2011.

POUDAT, C. Étude contrastive de l'article scientifique de revue linguistique dans une perspective d'analyse des genres. Thèse de doctorat: Université d'Orléans, 2006.

RASTIER, F. Idéologie et théorie des signes. La Haye: Mouton, 1971.

Sémantique interprétative. Paris: PUF, 1987. 2e éd. augmentée, 1996. 3e éd., 2009.

Sémantique et recherches cognitives. Paris: PUF, 1991.

Problems of cognitive semantics. In: MANJALI, F. D. (Ed.). Language and Cognition. New Dehli: Bahri Publications, 1993.

. Meaning and Textuality. Toronto University Press, 1997 (tr. anglaise par Frank Collins et Paul Perron de Sens et textualité. Paris: Hachette, 1989. Texte revu et augmenté).

. Sign and symbol. Semiotics and Cognitive science. In: MANJALI, F. (Ed.), Cognitive Science, New Delhi, Bahri Publications, 1998.

Prédication, actance et zones anthropiques. In: FORSGREN, M.; JONASSON, K.; KRONNING, H. (Eds.). Prédication, Assertion, Information, Uppsala. Acta Universitatis Uppsaliensis, 56, 1998.

. Representation or interpretation? Linguistics in the Morning Calm, 4, Séoul: The Linguistic Society of Korea, 1999.

. Cognitive Semantics and Diachrony. In: BLANK, A.; KOCH, P. (Eds.), Historical Semantics and Cognition. Mouton de Gruyter. Berlin, 1999.

. Arts et sciences du texte. Paris: PUF, 2001.

. Semantics for descriptions. Chicago University Press: CSLI Lectures Notes, 138, 2002.

. On signs and texts. Applied Semiotics/Sémiotique appliquée, II, 4-5, 2005.

Interview. In: STJERNFELD, F.; BUNDGAARD, P. (Eds.). Signs and Meaning RASTIER, F. Five Questions, s. I., Automatic Press, 2009.

. Passages and Paths within the Intertext, Belgian Journal of Linguistics, 23, 2009.

. Web Semantics vs the Semantic Web : the Problem of Keyness. In: Bondi, M.; SCOTT, M.

Keyness in Texts, Studies in Corpus Linguistics, 41, Amsterdam, Benjamins, 2010.

. La Mesure et le Grain. Sémantique de corpus. Paris: Champion, 2011.

Text semiotics: Between philology and hermeneutics - from the document to the work. Semiotica, 192, 2012.

Saussure au futur. Paris: Les Belles Lettres, 2015.

RASTIER, F.; BOUQUET, S. (Eds.). Une introduction aux sciences de la culture. Paris: PUF, 2002.

RASTIER, F.; FLOETTUM, K. (Eds.). Academic Discourse, Multidisciplinary Approaches. Oslo: Novus, 2003.

RASTIER, F.; VAletTE, M. (Eds.). Concepts en contexte. Paris: Champion (à par.). Roy, Thibault, Visualisations interactives pour l'aide personnalisée à l'interprétation d'ensembles documentaires. Thèse d'informatique, Université de Caen. 2007.

SAUSSURE, F. de, Écrits de linguistique générale. Paris: Gallimard, 2002.

TANGUY, L. Traitement automatique de la langue naturelle et interprétation: contribution à l'élaboration d'un modèle informatique de la sémantique interprétative. Thèse: Université de Rennes 1, 1997. 
THLIVITIS, T. Sémantique interprétative intertextuelle: assistance anthropocentrée à la compréhension des textes. Thèse d'informatique: Université de Rennes 1, 1998.

VAILLANT, P. Sémiotique des langages d'icônes. Paris: Champion. 1999.

La syntaxe, c'est de la sémantique. In: ABLALI et al. (Eds.). Documents, textes, œuvres. Rennes: PUR.

VALETTE, M. Conceptualisation and Evolution of Concepts. The example of French Linguist Gustave Guillaume. FLØTTUM, K.; RASTIER, F. (Eds.) Academic discourse - multidisciplinary approaches. Oslo: Novus Press, 2003.

VAXELAIRE, J.-L. Les noms propres - Une analyse lexicologique et historique. Paris, Champion, 2005.

Texto recebido em 01/08/2019

e aprovado em 25/10/2019. 